\title{
ALTERAÇÕES NOS INDICADORES FINANCEIROS DAS COMPANHIAS DO SETOR DE ATACADO E VAREJO DECORRENTES DA NOVA CONTABILIZAÇÃO DO ARRENDAMENTO MERCANTIL OPERACIONAL
}

\section{CHANGES IN THE FINANCIAL RATIOS OF THE WHOLESALE AND RETAIL SECTOR COMPANIES ARISING FROM THE NEW ACCOUNTING OF THE OPERATING LEASE}

\author{
Recebido: 5/8/2016- Aceito: 11/11/2016- Publicação: 21/11/2016 \\ Processo de Avaliação: Double Blind Review
}

\author{
Mariana Moreira Arrozio \\ Graduada em Ciências Contábeis pela Faculdade Fipecafi \\ Fipecafi
}

\author{
Alexandre Gonzales ${ }^{1}$ \\ Doutor em Controladoria e Contabilidade pela USP \\ Professor da FIPECAFI e da PUC/SP
}

Fabiana Lopes da Silva

Doutora em Controladoria e Contabilidade pela USP

Professora da FIPECAFI e da PUC/SP

\section{RESUMO}

Em estudo recente, divulgado pelo International Accounting Standard Board (IASB), as mudanças nos critérios de contabilização do arrendamento mercantil adicionarão US\$2 trilhões aos balanços das companhias americanas. Este impacto é motivado, principalmente, pelas características contábeis que o arrendamento mercantil operacional possui, item off balance. Neste sentido, essa pesquisa analisou as operações de arrendamento mercantil operacional das companhias de atacado e varejo, qualificadas como arrendatárias, e os impactos da publicação da IFRS 16 como seu determinante. O estudo baseou-se na extração das informações contábeis publicadas nos demonstrativos financeiros das companhias listadas na bolsa de valores brasileira BMF\&Bovespa. A técnica estatística utilizada no estudo foi o teste dos postos com sinais de Wilcoxon. Os resultados obtidos por meio dos indicadores de Liquidez, Endividamento e de Alavancagem, calculados com base nas demonstrações financeiras publicadas em 2015 e nas demonstrações ajustadas conforme notas explicativas, possuem impacto significativo na estrutura patrimonial dessas companhias. Revelaram um aumento no nível de endividamento, na alavancagem financeira e queda na liquidez, observados pelo reconhecimento de novos ativos e passivos.

Palavras Chave: Arrendamento Mercantil Operacional, IFRS 16, Indicadores Financeiros.

\footnotetext{
${ }^{1}$ Autor para correspondência: Faculdade Fipecafi Rua Maestro Cardim, 1.170, Bela Vista - São Paulo - SP, Brasil , CEP: 01323-001.
} 


\begin{abstract}
In a recent study, released by the International Accounting Standard Board (IASB), changes in lease accounting criteria will add $\$ 2$ trillion to the balance sheets of US companies. This impact is mainly due to the accounting characteristics that the operating lease has, off balance item. In this sense, this research analyzed the operating leasing operations of the wholesale and retail companies, qualified as lessees, and the impacts of the publication of IFRS 16 as its determinant. The study was based on the extraction of the accounting information published in the financial statements of the companies listed on the Brazilian BMF \& Bovespa stock exchange. The statistical technique used in the study was the Wilcoxon signed rank test. The obtained results with use of the Liquidity, Debt and Leverage ratios, calculated on the basis of the financial statements published in 2015 and the adjusted statements according to the disclosure, have a significant impact on the equity structure of these companies. They revealed an increase of debt level, financial leverage and in liquidity, observed by the recognition of new assets and liabilities.
\end{abstract}

Keywords: Operating Lease, IFRS 16, Financial Ratios.

\title{
INTRODUÇÃO
}

A contabilidade é a principal ferramenta de comunicação entre os agentes econômicos. Com o desenvolvimento do mercado de capitais e das companhias, novas perspectivas despontaram no horizonte contábil. A existência de práticas contábeis peculiares no mundo incitou à convergência das normas contábeis. Sob essa perspectiva, surgem, portanto, as normas internacionais de contabilidade cujo objetivo é prover informações transparentes, confiáveis e comparáveis a todos os usuários das informações contábeis e financeiras.

No Brasil, o órgão responsável pelo preparo e emissão de Pronunciamentos Técnicos de Contabilidade aderentes à convergência da Contabilidade Brasileira aos padrões internacionais é o Comitê de Pronunciamentos Contábeis (CPC). O CPC foi criado pela Resolução CFC $n^{\circ}$ 1.055/05 e idealizado a partir da comunhão de seis entidades: o Conselho Federal de Contabilidade (CFC), a Associação dos Analistas e Profissionais de Investimento do Mercado de Capitais (APIMEC), a Associação Brasileira das Companhias Abertas (ABRASCA), a Bolsa de Mercadorias, Valores Futuros (BM\&F BOVESPA), a Fundação Instituto de Pesquisas Contábeis Atuariais e Financeiras (FIPECAFI) e o Instituto dos Auditores Independentes do Brasil (IBRACON).

O processo de adoção das normas internacionais de contabilidade teve início com a aprovação da Lei $n^{\circ} 11.638 / 07$ que, juntamente com a Lei $n^{\circ} 11.941 / 09$, forneceu o arcabouço legal para a adoção das normas interacionais no Brasil. No início do ano de 2010, o CFC e o CPC assinaram um memorando de entendimento com o IASB assumindo o ano de 2010 como data base para a plena convergência com as International Financial Reporting Standards (IFRS). As normas internacionais de contabilidade emitidas pelo IASB estão sendo implementadas no Brasil pelo CPC e pelos órgãos reguladores brasileiros desde então. 
O IASB é um comitê de normas internacionais de contabilidade, independente, criado com o objetivo de estudar, preparar e emitir normas de padrões internacionais de contabilidade, as IFRS. As normas emitidas pelo IASB são referências técnicas que não possuem natureza obrigatória, apenas propiciam a interpretação mais harmônica das informações contábeis pelos usuários destas informações (Niyama \& Silva 2013).

O Financial Accounting Standards Board (FASB) é um órgão de iniciativa privada, normatizador, responsável pelo estabelecimento de normas que orientem a elaboração dos relatórios financeiros, conhecidos como United States Generally Accepted Accounting Principles (US GAAP). Essas normas devem ser seguidas por todas as empresas que possuem suas ações e títulos em Bolsa de Valores Norte-Americana e são oficialmente reconhecidas pela Securities and Exchange Commission (SEC) e pelo American Institute of Certified Public Accountants (AICPA).

No ano de 2002, o FASB e o IASB anunciaram a emissão de um memorando de entendimento, conhecido como acordo de Norwalk. Com ele, o FASB comprometeu-se, por meio de seis iniciativas, promover a convergência dos USGAAP com as IFRS. Em 2006, os dois comitês adicionaram em suas respectivas agendas um projeto conjunto propondo mudanças na contabilização das operações de arrendamento mercantil. Como resultado deste esforço inicial, em 2010, a publicação do Exposure Draft Leases ED/2010/9 trouxe extenso feedback para ambos (International Accounting Standards Board, 2010b).

Em outubro de 2015, o IASB publicou uma sucinta atualização de projeto chamada Definition of a Lease. Este documento complementa o Project Update Leases: Definition of a Lease publicado em fevereiro de 2015 e explicita as decisões do IASB quanto à definição de arrendamento mercantil e como o FASB tem respondido os comentários recebidos sobre o Revised Exposure Draft 2010/9. Não obstante, em janeiro de 2016, o IASB emitiu seu novo pronunciamento, IFRS 16 Leases, que passa a vigorar a partir de $1^{\circ}$ de janeiro de 2019. As companhias podem aderir à nova norma antes de 2019, no entanto, deverão aderir igualmente à IFRS 15 Revenue from Contracts with Customers (International Accounting Standards Board, 2016).

Ribeiro (2015), em pesquisa divulgada pelo boletim da Associação Brasileira das Empresas de Leasing (ABEL), afirma que "um ponto que vem gerando polêmica e expectativa em relação ao leasing é a perspectiva de mudanças nas regras contábeis”. Dessa forma, se concretizadas as propostas incitadas pelos órgãos serão observados, nos balanços das companhias, registros que eram divulgados, apenas, em notas explicativas.

Portanto, em virtude das alterações que podem vir a ser introduzidas, é possível chegar ao seguinte problema de pesquisa: como as mudanças propostas pela IFRS 16 podem impactar os indicadores financeiros das companhias de capital aberto que possuem contratos de arrendamento mercantil operacional?

Diante disto, surge a intenção de refletir o objeto em questão, dado seu valor preditivo. A partir da IFRS 16, é possível identificar alterações qualitativas e quantitativas nas demonstrações contábeis e avaliar seus reflexos.

O objetivo geral deste estudo é apresentar os reflexos das mudanças propostas pelo ED/2010/9, concretizadas pela IFRS 16, na contabilização do arrendamento operacional nos balanços das companhias abertas que possuem contratos de arrendamento mercantil operacional na qualidade de arrendatárias. 
Como objetivos secundários têm-se: i) Identificação do nível de disclosure evidenciado em notas explicativas das companhias abertas que possuem contratos de arrendamento mercantil operacional na qualidade de arrendatárias, ii) Mensurar os impactos exigidos pela IFRS 16 nos demonstrativos contábeis das companhias de capital aberto, na qualidade de arrendatárias e iii) Avaliar o impacto a partir das exigências da IFRS 16 na estrutura de capital das companhias que possuem contratos de arrendamento mercantil operacional, na qualidade de arrendatárias.

Em vista disso, foram analisadas 17 companhias do setor de atacado e varejo que divulgaram em seus demonstrativos financeiros, informações relativas às transações de arrendamento mercantil operacional. A técnica estatística utilizada é o teste dos postos com sinais de Wilcoxon.

O trabalho está organizado de forma que na seção 2 é feita uma revisão literária e de conceitos sobre o arrendamento mercantil operacional; na seção 3 são apresentados os dados e os procedimentos estatísticos utilizados; a seção 4 revela os resultados da pesquisa e, por fim, a seção 5 evidencia as considerações finais.

\section{REFERENCIAL TEÓRICO}

Segundo dados da ABEL (2015), a atividade de arrendamento mercantil nasce, no Brasil, na década de 1960 durante o milagre econômico. O primeiro dispositivo legal que trouxe regulamentação às operações de arrendamento mercantil no Brasil foi a Lei $\mathrm{n}^{\circ}$ 6.099/74. Mais tarde, alterações introduzidas pela Lei $n^{\circ}$ 7.132/83 definiram o arrendamento mercantil como

o negócio jurídico realizado entre pessoa jurídica, na qualidade de arrendadora, e pessoa física ou jurídica, na qualidade de arrendatária, e que tenha por objeto o arrendamento de bens adquiridos pela arrendadora, segundo especificações da arrendatária e para uso próprio desta.

Essa legislação definiu tratamento tributário e transferiu a responsabilidade ao Conselho Monetário Nacional (CMN) e ao Banco Central do Brasil (BACEN) (Niyama \& Silva, 2013).

De acordo com Barbosa, Barros, Niyama e Souza (2011), a Resolução CMN n ${ }^{0}$ 2309/96 trouxe a segregação das operações de arrendamento mercantil em financeiro e operacional.

Iudícibus et al. (2013) afirmam que, anteriormente à Lei $\mathrm{n}^{\circ}$ 11.638/07, tanto o arrendamento mercantil operacional e financeiro eram classificados, contabilmente, como despesa no arrendatário quando do vencimento das parcelas. Nenhum ativo ou passivo eram registrados porque não se entendia que o arrendatário possuía a propriedade dos bens arrendados. 
Esse tratamento mudou, pois o artigo 179 da Lei $n^{\circ}$ 6.404/76, alterado pela 11.638/07, define como parte integrante do ativo imobilizado "os direitos que tenham por objeto bens corpóreos destinados à manutenção das atividades da companhia ou da empresa ou exercidos com essa finalidade, inclusive os decorrentes de operações que transfiram à companhia os benefícios, riscos e controle desses bens.”.

O CPC 06 (R1) Operações de Arrendamento Mercantil seguiu o modelo do International Accounting Standard (IAS) 17 para o atendimento à convergência das normas brasileiras com às internacionais (Iudícibus et al., 2013),

Ao analisar o CPC 06 (R1), percebe-se que o pronunciamento é uma tradução da IAS 17 (Ernst\&Young \& Fipecafi, 2010).

A classificação adotada pelo CPC observa a essência da transação e não a forma do contrato, sobretudo a responsabilidade de quem assumirá os riscos e benefícios inerentes a propriedade do bem (Iudícibus et al., 2013).

O arrendamento mercantil é "um acordo pelo qual o arrendador transmite ao arrendatário em troca de um pagamento ou série de pagamentos o direito de usar um ativo por um período de tempo acordado” (CPC, 2010).

Um arrendamento mercantil pode ser decomposto entre arrendamento mercantil financeiro e arrendamento mercantil operacional. Para isso é necessário analisar suas características e realizar sua classificação no início do contrato. (Iudícibus et al., 2013).

A classificação adotada pelo pronunciamento técnico CPC 06 R1 (2010) apresenta o arrendamento mercantil financeiro como "aquele em que há transferência substancial dos riscos e benefícios inerentes à propriedade de um ativo. $\mathrm{O}$ título de propriedade pode ou não vir a ser transferido” (p.3). O arrendamento mercantil operacional, como define o mesmo pronunciamento, "é um arrendamento diferente de um arrendamento mercantil financeiro" (p.3).

Barbosa, Barros, Niyama e Souza (2011) afirmam que um fator importante a ser analisado é a classificação, pois os critérios variam de país a país, mas o arrendamento financeiro se aproxima a uma venda financiada, já o operacional assemelha-se a uma locação de determinado bem.

De acordo com o item 33 do CPC 06 R1 (2010), “os pagamentos da prestação do arrendamento mercantil operacional devem ser reconhecidos como despesa na base da linha reta durante o prazo do arrendamento mercantil, exceto se outra base sistemática for mais representativa do padrão temporal do benefício do usuário” (p.11).

O CPC 06 R1 (2010) destaca que os pagamentos da prestação, excluindo os custos de serviços tais como seguro e manutenção, devem ser reconhecidos como despesa na base da linha reta, ainda que tais pagamentos não sejam feitos nessa base. Outro fator de destaque são as divulgações relativas às operações de arrendamento mercantil operacional. O pronunciamento recomenda que sejam divulgados os valores presentes dos pagamentos mínimos futuros dos arrendamentos mercantis operacionais não canceláveis até 1 ano, de 1 a 5 anos e mais de 5 anos. 


\subsection{Operações de Arrendamento Mercantil Financeiro e Operacional nas demonstrações do arrendatário segundo IASB}

Em 1982, a International Accounting Standards (IAS 17) foi emitida pelo International Accounting Standards Committee (IASC) tendo validade após $1^{\circ}$ de janeiro de 1984.

Ernst\&Young e Fipecafi (2010) afirmam que o pronunciamento teve como base o então pronunciamento do Reino Unido Statements of Standard Accounting Practice (SSAP) 21. Mais tarde, diversos projetos de revisão foram efetuados. A última revisão foi realizada em 2003, sendo vigente em 2005. Nela, a norma dava tratamento específico à classificação de arrendamento de terrenos e edifícios, que por ora não tinham considerações específicas.

Iudícibus et al. (2013) destacam que, com o objetivo de correlacionar as normas contábeis brasileiras às normas internacionais, foi emitido o Pronunciamento Técnico CPC 06, baseado no IAS 17 do IASB, aprovado e tornando-se obrigatório para as companhias abertas pela deliberação da CVM n ${ }^{0}$ 554/08.

Segundo Ernst\&Young e Fipecafi (2010), nos últimos anos, vários contratos têm sido customizados de tal forma que sua essência jurídica não permite afirmar que se trata de uma operação de arrendamento, entretanto, uma análise mais aprofundada revela que na essência se trata efetivamente de um contrato de arrendamento.

Sob essa perspectiva, o International Financial Reporting Interpretation Committee (IFRIC) emitiu o IFRIC 4, servindo de base para a Interpretação Técnica (ICPC) 03, apresentando um consenso sobre a determinação de um arrendamento mercantil: este deve estar pautado na essência do contrato, e uma avaliação sobre dois aspectos deve ser considerada; o cumprimento do acordo depende do uso de ativo ou ativos específicos e o acordo transfere o direito de usar o ativo (Ernst\&Young \& Fipecafi, 2010).

Assim como há contratos que na essência são arrendamento, embora sua substância jurídica não o classifique assim, o inverso também é verdadeiro. Essa questão é abordada pelo Standard Interpretation Committee (SIC) por meio do SIC 27 que lida com a avaliação da substância das transações numa operação que assume forma legal de contrato de arrendamento (Ernst\&Young \& Fipecafi, 2010).

Um arrendamento pode ser classificado como financeiro ou operacional. Uma vez classificado, não poderá sofrer alteração de classificação, salvo mudanças contratuais de maneira substancial que mudem a natureza do contrato.

A IAS 17 define um arrendamento mercantil financeiro como aquele que transfere substancialmente todos os riscos e benefícios inerentes à propriedade de um ativo. A propriedade pode ser ou não transferida. No reconhecimento inicial de um arrendamento mercantil financeiro, o ativo e o passivo provenientes de um contrato devem ser reconhecidos pelo valor presente das parcelas mínimas obrigatórias ou do seu valor justo de mercado; dos dois, o menor.

Iudícibus et. al (2013) destacam que dessa forma se abandona o custo histórico como base de valor para a contabilização do leasing financeiro. 
Barbosa, Barros, Niyama e Souza (2011) enfatizam que os custos iniciais devem ser diretamente atribuídos à negociação no custo inicial do ativo e a taxa de juros utilizada na determinação do valor presente dos pagamentos mínimos deve ser a taxa de juros implícita na operação.

Quanto à mensuração subsequente, a IAS 17 preocupa-se em distinguir dois tipos de ativos para fins de depreciação: aqueles em que haverá transferência de propriedade ao final do contrato e aquele em que não haverá. No primeiro caso, é razoável admitir que a depreciação será efetuada com base na vida útil estimada do bem; por outro lado a depreciação ou amortização deveria ser efetuada de acordo com a duração prevista do contrato de arrendamento ou a vida útil; dos dois, o menor (Iudícibus et. al, 2013).

A IAS 17 exige uma divulgação detalhada pelos arrendatários nos contratos de arrendamento operacional e financeiro. As notas explicativas devem conter, no mínimo, as informações relativas às características gerais dos contratos de arrendamento financeiro, valores brutos dos ativos registrados em contrato e as contraprestações e valores residuais a pagar, decorrentes de arrendamento (Ernst\&Young \& Fipecafi, 2010).

Em relação ao passivo, a IAS 17 prevê a reconciliação das parcelas mínimas obrigatórias pelo seu valor nominal de pagamento para os correspondentes valores presentes dessas parcelas. Também estabelece uma divulgação dos pagamentos a serem efetuados até um ano, de um a cinco anos e posteriores cinco anos. Observando a mesma obrigatoriedade de divulgação do arrendamento mercantil financeiro, a IAS 17 requer uma divulgação, no mínimo, (a) das características gerais dos contratos de arrendamento financeiro, (b) do valor bruto dos ativos registrados em contrato e (c) da contraprestação e valores residuais a pagar, decorrentes de arrendamento (Ernst\&Young \& Fipecafi, 2010).

Segundo Ernst\&Young e Fipecafi (2010), a classificação de um contrato de arrendamento mercantil operacional ocorre por exclusão. A classificação depende mais da substância da transação do que da forma do contrato.

Quanto ao reconhecimento inicial do arrendamento operacional nas demonstrações dos arrendatários, a IAS 17 define que os pagamentos referentes ao arrendamento mercantil operacional devem ser reconhecidos como despesa numa base de linha reta durante o prazo do arrendamento, salvo se uma outra base sistêmica for mais representativa (Ernst\&Young \& Fipecafi, 2010).

Isso se deve ao fato de que este tipo de arrendamento é mais compatível com características de aluguel do que uma compra financiada. (Iudícibus et. al, 2013)

\subsection{Contribuições do Exposure Draft 2010/9 e Revised Exposure Draft 2013/6 à IFRS 16 sob a ótica do arrendatário}

Em 2016, o IASB divulgou a IFRS 16 Leases que estabelece princípios para reconhecimento, mensuração, apresentação e divulgação das atividades de arrendamento mercantil. Com validade inicial a partir de 1 de janeiro de 2019, sua adoção antecipada é permitida, desde que as entidades elegíveis apliquem a IFRS 15 antes da data inicial de 
vigência da norma do leasing. A IFRS 16 (International Accounting Standards Board , 2016) destaca que

o leasing é uma atividade importante para muitas entidades. É um meio de ter acesso aos bens, de obtenção de financiamento e de redução da exposição da entidade aos riscos de propriedade de ativos. A prevalência de locação significa que é importante que os usuários das demonstrações financeiras tenham uma imagem completa e compreensível de locação atividades da entidade (p.6).

De acordo com o IASB (2016), o modelo anterior foi duramente criticado por não satisfazer as necessidades dos usuários das demonstrações financeiras, pois não fornecia uma representação fiel das operações de arrendamento mercantil, em particular, o fato de arrendatários de operações de arrendamento operacional não reconhecerem ativos e passivos provenientes dessas operações.

Essa nova abordagem visa uma representação mais fiel da posição financeira e maior transparência sobre informações relativas à alavancagem financeira e ao capital investido pelo arrendatário (International Accounting Standards Board, 2016).

A publicação do ED/2010/9, como lembra IASB (2016), contribuiu de forma positiva para se chegar a uma proposta aderente de mudança na contabilização das operações de arrendamento mercantil.

Batista e Formigoni (2013) asseveram que, em 2013, a publicação de uma nova minuta incluía propostas a respeito do padrão de contabilização e divulgação dos contratos de arrendamento, mantendo, no entanto, a proposta original de avaliação das operações de arrendamento mercantil com base em um padrão único, sem distinguir os contratos de arrendamento financeiro dos contratos de arrendamento operacional.

O relatório Snapshot: Leases, publicado em 2013 pelo IASB e FASB, esclarecia que os usuários externos ajustavam manualmente as demonstrações contábeis publicadas a fim de refletir a realidade das operações do arrendamento operacional nos demonstrativos e ressaltava sua preocupação escancarando a necessidade de aprimorar a qualidade e a comparabilidade dos relatórios financeiros publicados (Batista \& Formigoni,2013).

No ano seguinte, após a publicação do Project Uptade - Practical Implications of the new Leases Standard, observou-se a existência de dois possíveis modelos de contabilização e suas diferenças e semelhanças. Também foram fornecidos alguns possíveis efeitos das alterações futuras no arrendatário.

Os boards decidiram, a partir da IFRS 16, que um arrendatário deveria ser obrigado a reconhecer ativos e passivos para todos os contratos de arrendamento, salvo exceções limitadas, e ambos definiram a operação de arrendamento mercantil operacional da mesma forma (International Accounting Standards Board, 2016).

Por outro lado, o IASB decidiu adotar um modelo único de contabilização pelo qual um arrendatário contabiliza todas as operações de arrendamento da mesma forma. O FASB decidiu adotar dois modelos de contabilização pelo arrendatário, de maneira similar aos requisitos anteriores nos princípios geralmente aceitos, US GAAP, para distinguir entre 
arredamento operacional e arrendamento financeiro (International Accounting Standards Board, 2016).

Ao arrendatário é necessário reconhecer um direito de uso, que representa seu direito de uso do ativo arrendamento e uma responsabilidade pelo arrendamento, que representa a sua obrigação de fazer pagamentos da locação (International Accounting Standards Board, 2016).

A mensuração do direito de uso de ativos deverá ser feita da mesma forma que outros ativos não financeiros, tais como propriedade, instalações e equipamentos o são, como consequência, o arrendatário reconhece a depreciação dos ativos de direito de uso. Os passivos devem ser mensurados da mesma forma que outros passivos financeiros o são (International Accounting Standards Board, 2016).

Os ativos e passivos resultantes de um contrato de arrendamento são inicialmente medidos em uma base de valor presente. A medida inclui pagamentos de locação não canceláveis, incluindo aqueles ligados à inflação, e também inclui pagamentos a efetuar em períodos opcionais se o arrendatário for razoavelmente certo de exercer uma opção para estender o contrato de arrendamento ou não exercer a opção de rescindir o contrato (International Accounting Standards Board, 2016).

Quanto aos requisitos de divulgação aplicáveis aos arrendatários, a IFRS 16 (International Accounting Standards Board, 2016) destaca que

Os arrendatários vão precisar aplicar juízo em decidir sobre as informações a divulgar para cumprir o objetivo de proporcionar uma base para os usuários das demonstrações financeiras avaliarem o efeito sobre a posição financeira, desempenho financeiro e fluxos de caixa do locatário locações. (p.7)

A norma prevê, em seu item de número 53, que o arrendatário divulgue: (a) a depreciação de ativos do direito de uso pela classe do ativo subjacente; (b) despesa de juros sobre os passivos de locação; (c) as despesas relativas a locações de curto prazo, não sendo necessário incluir a despesa relativa a locações com um prazo de locação de um mês ou menos; (d) as despesas relativas à locação de bens de baixo; (e) as despesas relativas a pagamentos de locação variável não incluídos na mensuração de passivos de locação; (f) receitas de sublocação de direito de uso bens; (g) saída de dinheiro total para locações; (h) adições ao direito de uso de bens; (i) ganhos ou perdas decorrentes de transações de venda e relocação; e (j) a realização do direito de uso de ativos no final do período de relato por classe de ativo subjacente (International Accounting Standards Board, 2016).

Além das divulgações exigidas, um arrendatário divulgará informações qualitativas e quantitativas adicionais sobre suas atividades de arrendamento necessárias para cumprir o objetivo de avaliar o efeito sobre a posição financeira, desempenho financeiro e fluxos provenientes de atividades de arrendamento. Essas informações adicionais podem incluir, mas não está limitada a informações que ajudam os usuários das demonstrações financeiras para avaliar: (a) a natureza do locatário de locação atividades; (b) fluxos ao qual o locatário é potencialmente exposto que não são refletidos na mensuração de passivos de locação. Isso inclui a exposição resultante: (i) pagamentos de locação variável; (ii) extensão opções e opções de finalização; (iii) valor residual; (iv) arrendamentos que ainda não começaram em 
que o locatário está empenhado; (c) restrições ou convênios impostos por arrendamentos; (d) venda e relocação transações (International Accounting Standards Board, 2016).

Portanto, tendo em vista as justificativas formuladas pelo IASB a respeito das mudanças na contabilização do arrendamento mercantil operacional, concretizadas pela IFRS 16, pode-se observar que o reconhecimento de um direito e de uma obrigação nas demonstrações das companhias, qualificadas como arrendatárias, impactariam a estrutura patrimonial e principalmente os indicadores de liquidez, endividamento e de alavancagem financeira.

\subsection{Análise de Indicadores}

Segundo Matarazzo (2010), “assim como um médico usa certos indicadores, como pressão arterial e temperatura, para elaborar o quadro clínico de um paciente, os indicadores financeiros permitem construir um quadro de avaliação da empresa” (p.82). Dessa forma, a leitura de índices financeiros permite uma visão macro da saúde econômica e financeira de uma entidade.

Nesse sentindo, Martins, Diniz e Miranda (2014) advertem que a quantidade de índices não é determinante para uma análise de qualidade, mas somente aqueles necessários à compreensão da situação observada.

Assaf (2012) assegura que um índice isolado dificilmente contribuirá com informações relevantes. Ainda que uma série de outros índices complementares tenha sido mensurada, é indispensável uma confrontação temporal e setorial.

Neste contexto, Iudícibus (2010a) destaca que o uso de indicadores tem como finalidade a avaliação de padrões. A análise dos indicadores constitui mais do que uma retratação passada, ela propicia elementos para inferir tendências futuras.

Os indicadores selecionados, bem como sua fórmula de cálculo, são apresentados no quadro1. 


\section{Quadro 1 - Indicadores Financeiros}

\begin{tabular}{|c|c|c|}
\hline Indicador & Fórmula & Conceito \\
\hline Liquidez Corrente & $\frac{\text { Ativo Circulante }}{\text { Passivo Circulante }}$ & $\begin{array}{c}\text { É a relação de todo } \\
\text { disponível conversível em } \\
\text { curto prazo, com relação as } \\
\text { dívidas de curto prazo. }\end{array}$ \\
\hline Liquidez Geral & $\begin{array}{l}\text { Ativo Circulante }+ \text { Realizável } \\
\text { Longo Prazo } \\
\text { Passivo Circulante + Exigível } \\
\text { de Longo Prazo }\end{array}$ & $\begin{array}{l}\text { Este quociente serve para } \\
\text { detectar a saúde financeira de } \\
\text { longo prazo do } \\
\text { empreendimento. }\end{array}$ \\
\hline Capitais Terceiros / Próprios & $\frac{\text { Exigível Total }}{\text { Patrimônio Líquido }}$ & $\begin{array}{l}\text { Retrata o posicionamento das } \\
\text { companhias com relação ao } \\
\text { capital de terceiros. }\end{array}$ \\
\hline $\begin{array}{c}\text { Imobilização Patrimônio } \\
\text { Líquido }\end{array}$ & $\frac{\text { Ativo Imobilizado }}{\text { Patrimônio Líquido }}$ & $\begin{array}{l}\text { Retrata qual a porcentagem } \\
\text { dos recursos próprios que } \\
\text { está imobilizada em plantas e } \\
\text { instalações }\end{array}$ \\
\hline \multirow[t]{2}{*}{ Grau de Alavancagem } & $\begin{array}{c}\text { Lucro Líquido } \\
\text { Patrimônio Líquido } \\
\text { Lucro Líquido + Despesa } \\
\text { Financeira Líquida IR } \\
\end{array}$ & \multirow[t]{2}{*}{$\begin{array}{l}\text { Verifica o efeito do } \\
\text { endividamento sobre o lucro }\end{array}$} \\
\hline & Ativo Médio & \\
\hline
\end{tabular}

Fonte: Elaborada pelos autores com base em Iudícibus, 2010a.

Assaf (2012) assinala que os indicadores de liquidez visam medir a capacidade de pagamento de uma companhia, sendo a liquidez corrente uma medida de curto prazo e a liquidez geral uma medida que retrará a saúde financeira a longo prazo.

Os indicadores de endividamento e estrutura buscam compor a relação de fontes de recursos que uma empresa se utiliza. Segundo Assaf (202), a relação quociente de capital de terceiros sobre o capital próprio revela o nível de dependência da companhia em relação a seu financiamento por meio de recursos próprios. Quanto ao quociente de imobilização do patrimônio, ele revela o percentual dos recursos próprios (patrimônio líquido) que se encontra imobilizada no ativo.

Ademais, Nyama (2010) afirma que a avaliação da alavancagem financeira é a proporção com que uma companhia faz uso de capital de terceiros. O grau de alavancagem financeira de uma companhia evidencia os feitos das variações ocorridas no lucro antes dos juros e do importo de renda, que se refletem no Lucro Líquido. 


\section{MÉTODO DE PESQUISA}

Com o propósito de delimitar este estudo, optou-se por empregar, os critérios propostos por Vergara (2014), que qualifica um estudo quanto aos fins e quanto aos meios.

Quanto aos fins, o estudo pode ser qualificado como descritivo e explicativo. Descritivo porque propôs detalhar a contabilização do arrendamento mercantil operacional vigente e, paralelamente, descrever as mudanças na contabilização do arrendamento mercantil operacional nas companhias qualificadas como arrendatárias, concretizadas pela IFRS 16. Explicativo pois tais propostas foram mensuráveis e elegíveis a impactar, não somente demonstrativos, mas índices financeiros contábeis, sobretudo aqueles relacionados ao endividamento.

Quanto aos meios, o estudo pode ser qualificado como documental e bibliográfico. Documental, pois utilizou-se de demonstrativos financeiros auditados e publicados no site da CVM. Bibliográfico por utilizar-se de materiais tais como normativos, legislação, livros e artigos.

Para atender o objetivo do estudo de apresentar os reflexos das mudanças propostas na contabilização do arrendamento operacional das companhias que possuem contratos de arrendamento mercantil operacional na qualidade de arrendatárias, pensou-se, em um primeiro momento, estudar as companhias abertas do subsetor transporte.

A escolha desse subsetor foi motivada por dados divulgados pela Abel: a Associação de Leasing e Financiamento de Equipamentos (ELFA) nos EUA divulgou um volume de inversões em bens de capital e ativos fixos em 2013 avaliado em US\$1,4 trilhão, dos quais US\$ 903 bilhões foram financiados por leasing operacional ou por outras linhas de crédito, sendo os setores de transporte, aviação, automotivo, fluvial e ferroviário, os com maior participação da carteira com aproximadamente $26 \%$ dos investimentos.

Desta forma, surgiu a motivação em verificar o comportamento das companhias listadas no mercado brasileiro que divulgaram suas demonstrações em 2015. Foram selecionadas 12 companhias listadas na BMF\&Bovespa dos segmentos de transporte aéreo, transporte ferroviário, transporte hidroviário e transporte rodoviário.

Para a realização do estudo, era necessário que todas as empresas contidas na amostra, qualificadas como arrendatárias, obrigatoriamente, tivessem divulgado, em notas explicativas, o total dos futuros pagamentos mínimos do arrendamento mercantil ao final do período e o seu valor presente, para cada um dos seguintes períodos: até um ano, mais de um ano e até cinco e mais de cinco. Das empresas selecionadas, em cinco delas, os valores mínimos não foram localizados nas notas explicativas ou não foram divulgadas informações relativas às operações de arrendamento mercantil operacional.

Buscando conciliar a utilidade da informação a que este trabalho se propôs trazer e a disponibilidade dos dados necessários para a análise, partiu-se segmento. A escolha do segmento de atacado e varejo deu-se em função do ranking "Os 10 maiores setores em endividamento 2014”, segundo o Anuário Estatístico das Companhias Abertas 2015/2016 da Associação Brasileira das Companhias Abertas (ABRASCA, 2016). 
Conciliando o propósito do estudo de avaliar, também, o impacto na estrutura de capital das companhias, que possuem contratos de arrendamento mercantil operacional, na qualidade de arrendatárias, foram selecionadas 17 companhias listadas na BMF\&Bovespa que divulgaram suas demonstrações referentes 2015 e evidenciaram, em notas explicativas, as informações relativas às operações de arrendamento mercantil operacional. As companhias selecionadas são apresentadas na Tabela 1.

Foram coletadas das demonstrações financeiras informações referentes ao Ativo Realizável a Curto Prazo, Ativo Realizável a Longo Prazo, Passivo Exigível a Curto Prazo, Passivo Exigível a Longo Prazo, Patrimônio Líquido, Lucro Líquido e Despesa Financeira. Das notas explicativas foram extraídas as informações divulgadas a respeito do arrendamento mercantil operacional.

Com base nessas informações, foi possível calcular os indicadores utilizados na análise. A escolha dos indicadores deu-se em função dos critérios difundidos e observados em Iudícibus (2010a). Os indicadores calculados foram apresentados no referencial teórico.

Consequentemente, os resultados obtidos nesta pesquisa não podem ser generalizados para todas as companhias brasileiras de atacado e varejo, mas apenas para as empresas apresentadas.

$\mathrm{Na}$ primeira parte da análise, a lógica constituiu-se em analisar as diferenças existentes entre os indicadores calculados com os dados publicados em 2015, sem a influência das informações sobre o arrendamento mercantil operacional, e depois considerando os impactos da contabilização do arrendamento mercantil operacional nas informações divulgadas em 2015. Os índices de liquidez, endividamento e alavancagem obtidos com base nas informações divulgadas em nota explicativa são verificados na tabela 2.

Os resultados obtidos, considerando a adoção inicial da IFRS 16, indicaram uma redução da liquidez corrente em 16 companhias (94\%). Observou-se uma queda acentuada nas companhias Dimed S.A. (-17,2\%), Lojas Marisa S.A (-32,5) e Raia Drogasil (-15,7\%). Este efeito se dá em função do reconhecimento de dívidas de curto e longo prazo que, seguindo os preceitos do CPC 06 R1 e IAS17, não estavam contabilizadas no passivo, itens off balance.

Logo, partiu-se para a escolha do teste estatístico que fosse capaz de responder se existiriam diferenças significativas nos indicadores de liquidez, endividamento e alavancagem destas companhias antes e depois da adoção da IFRS 16.

Contudo, antes da escolha do teste estatístico para realizar as inferências acerca da amostra, foi necessário verificar se a amostra possuía distribuição normal. Para avaliar a normalidade de uma amostra os testes mais adequados são o de Kolmogorov - Smirnov (K-S) e o de Shapiro - Wilk (S-W).

O teste K-S é um teste de aderência que procura determinar se uma amostra é proveniente de uma população com distribuição normal. O teste S-W também testa se a variância em estudo possui ou não distribuição normal.

De acordo com Maroco (2007, citado por Fávero, Belfiore, Silva \& Chan, 2009) o teste de S-W é mais apropriado que o teste K-S, quando as amostras são pequenas, $\mathrm{n}<30$. Dado o perfil da amostra em estudo, o teste escolhido foi o S-W. 
Por meio do pacote estatístico SPSS, foram efetuados os Testes de Normalidade de S-W. A estatística aplicada considerou o nível de significância $\alpha=5 \%$. O SPSS calcula o pvalue que corresponde ao menor nível de significância observado que levaria à rejeição da hipótese nula. A hipótese nula $\mathrm{H} 0$ afirma que a amostra provém de uma população normal. A hipótese alternativa H1 afirma que a amostra não provém de uma população normal. Os dados obtidos são apresentados na Tabela 3.

Ao lançar os indicadores financeiros de liquidez, endividamento e alavancagem no programa SPSS, foram obtidos os valores dos p-values. Como todos os valores dos p-values obtidos são inferiores a $5 \%(\alpha=5 \%)$, verifica-se que a amostra deste estudo não possui distribuição normal.

Dada a não normalidade da amostra, foi usado o teste não paramétrico de Wilcoxon a fim de avaliar se existiriam diferenças significativas nos indicadores de liquidez, endividamento e alavancagem antes e após a adoção da IFRS 16.

Para o teste de Wilcoxon, a hipótese nula H0 implica que os indicadores calculados com base nas informações publicadas em 2015 e os indicadores ajustados não apresentaram diferenças significativas. A hipótese $\mathrm{H} 1$ implica que os indicadores calculados com base nas informações publicadas em 2015 e os indicadores ajustados dão indícios de que existem diferenças significativas. Os dados obtidos são apresentados na Tabela 4.

Com relação ao indicador de liquidez geral, as 17 companhias apresentaram um recuo, tendo como destaque as companhias Dimed S.A (-49,0\%), Lojas Marisa S.A. (-32,0\%) e Raia Drogasil (-38,8\%). Os indicadores de liquidez apresentados sinalizam a capacidade destas companhias em assumir suas dívidas.

Nota-se, também, um aumento no nível de endividamento da amostra. Destaque para Dimed S.A. (96,2\%), Lojas Marisa (47,1\%) e Raia Drogasil (63,5\%). O índice de endividamento indica a dependência que a entidade apresenta de terceiros e, nesse sentido, o risco a que está sujeita.

Por fim, observou-se um aumento no grau de alavancagem de 12 companhias, destacando-se as companhias Dimed S.A com aumento de 56\%, Lojas Renner com aumento de $27 \%$ e Raia Drogasil com aumento de $29 \%$.

O reconhecimento do arrendamento mercantil operacional nas demonstrações contábeis das companhias de atacado e varejo, em linhas gerais, indicou diminuição da liquidez, aumento do endividamento e aumento na alavancagem.

Nota-se que as informações divulgadas pelas empresas brasileiras não estão totalmente adequadas aos requisitos do CPC 06 (R1). Iudícibus (2010b) afirma que a evidenciação é um compromisso inalienável da Contabilidade com seus usuários, pois a apresentação das informações quantitativas e qualitativas propiciam base adequada de informação para os usuários. Dessa forma, nota-se a relevância do processo de evidenciação e divulgação das informações na medida em que estas procuram atender diferentes tipos de usuários.

O estudo teve por objetivo avaliar o impacto da adoção da IFRS 16 nos indicadores das companhias de atacado e varejo listadas na bolsa de valores brasileira, tendo como base as mudanças causadas nos principais indicadores. 
Para atingir o objetivo proposto, foi necessário seu desmembramento em três objetivos específicos: i) identificar o nível de disclosure evidenciado em notas explicativas das companhias abertas que possuem contratos de arrendamento mercantil operacional na qualidade de arrendatárias, ii) mensurar os impactos concretizados pela IFRS 16 nos demonstrativos contábeis das companhias de capital aberto, na qualidade de arrendatárias e iii) avaliar o impacto, a partir das propostas da IFRS16, na estrutura de capital das companhias que possuem contratos de arrendamento mercantil operacional, na qualidade de arrendatárias.

Os resultados obtidos sugerem que o leasing produz efeitos sob a liquidez, o endividamento e também sobre a alavancagem operacional.

Cabe ressaltar que os resultados obtidos corroboram pesquisas anteriores - Barbosa, Barros, Niyama e Souza (2011), Gallon, et al (2012), Batista e Formigoni (2013) - sobre os impactos do arrendamento mercantil na estrutura de ativos e passivos e nos indicadores financeiros.

Limitação relevante para o estudo é o fato de que muitas companhias não apresentaram em suas informações de 2015 a recomendação que o CPC 06 R1 propõe no tocante ao nível de disclosure necessário à divulgação das operações de arrendamento mercantil. Adicionalmente, não fizeram parte do escopo do trabalho, representando desta forma uma limitação, os efeitos da mensuração subsequente da IFRS 16. Não foram consideradas as taxas de depreciação dos ativos relativos ao arrendamento operacional, taxas de desconto para o cálculo do valor presente das parcelas futuras.

Sugere-se que em estudos futuros sejam abordados, comparativamente, os impactos das alterações analisadas no presente trabalho em segmentos distintos, com a finalidade de identificar como cada um deles se comporta, permitindo uma maior compreensão da realidade de cada atividade.

para a seleção de outro segmento. A escolha do segmento de atacado e varejo deu-se em função do ranking “Os 10 maiores setores em endividamento 2014”, segundo o Anuário Estatístico das Companhias Abertas 2015/2016 da Associação Brasileira das Companhias Abertas (ABRASCA, 2016).

Conciliando o propósito do estudo de avaliar, também, o impacto na estrutura de capital das companhias, que possuem contratos de arrendamento mercantil operacional, na qualidade de arrendatárias, foram selecionadas 17 companhias listadas na BMF\&Bovespa que divulgaram suas demonstrações referentes 2015 e evidenciaram, em notas explicativas, as informações relativas às operações de arrendamento mercantil operacional. As companhias selecionadas são apresentadas na Tabela 1. 
Tabela 1 - Companhias Abertas dos Segmentos de Atacado e Varejo na BMF\&Bovespa em 30 de março de 2016

\begin{tabular}{|c|c|}
\hline \multicolumn{2}{|r|}{ Companhias } \\
\hline 1 & Arezzo Indústria e Comércio S.A. \\
\hline 2 & B2W Companhia Digital S.A. \\
\hline 3 & Brasil Pharma S.A. \\
\hline 4 & DIMED S.A. \\
\hline 5 & Guararapes Confecções S.A. \\
\hline 6 & Cia Hering S.A. \\
\hline 7 & Hypermarcas S.A. \\
\hline 8 & Restoque Comércio e Confecção de Roupas S.A. \\
\hline 9 & Lojas Americanas S.A. \\
\hline 10 & Lojas Marisa S.A. \\
\hline 11 & Lojas Renner S.A. \\
\hline 12 & Magazine Luiza S.A. \\
\hline 13 & Natura Cosméticos S.A. \\
\hline 14 & Companhia Brasileira de Distribuição S.A. \\
\hline 15 & Raia Drogasil S.A. \\
\hline 16 & Saraiva S.A. \\
\hline 17 & Via Varejo S.A. \\
\hline
\end{tabular}

Fonte: Elaborada pelos autores com base nas informações disponíveis no Anuário Estatístico das

Companhias Abertas 2015/2016 Abrasca, 2016.

Foram coletadas das demonstrações financeiras informações referentes ao Ativo Realizável a Curto Prazo, Ativo Realizável a Longo Prazo, Passivo Exigível a Curto Prazo, Passivo Exigível a Longo Prazo, Patrimônio Líquido, Lucro Líquido e Despesa Financeira. Das notas explicativas foram extraídas as informações divulgadas a respeito do arrendamento mercantil operacional.

Com base nessas informações, foi possível calcular os indicadores utilizados na análise. A escolha dos indicadores deu-se em função dos critérios difundidos e observados em Iudícibus (2010a). Os indicadores calculados foram apresentados no referencial teórico.

Consequentemente, os resultados obtidos nesta pesquisa não podem ser generalizados para todas as companhias brasileiras de atacado e varejo, mas apenas para as empresas apresentadas.

\section{ANÁLISE DOS RESULTADOS}

$\mathrm{Na}$ primeira parte da análise, a lógica constituiu-se em analisar as diferenças existentes entre os indicadores calculados com os dados publicados em 2015, sem a influência das informações sobre o arrendamento mercantil operacional, e depois considerando os impactos da contabilização do arrendamento mercantil operacional nas informações divulgadas em 2015. Os índices de liquidez, endividamento e alavancagem obtidos com base nas informações divulgadas em nota explicativa são verificados na tabela 2. 
Tabela 2 - Indicadores Financeiros

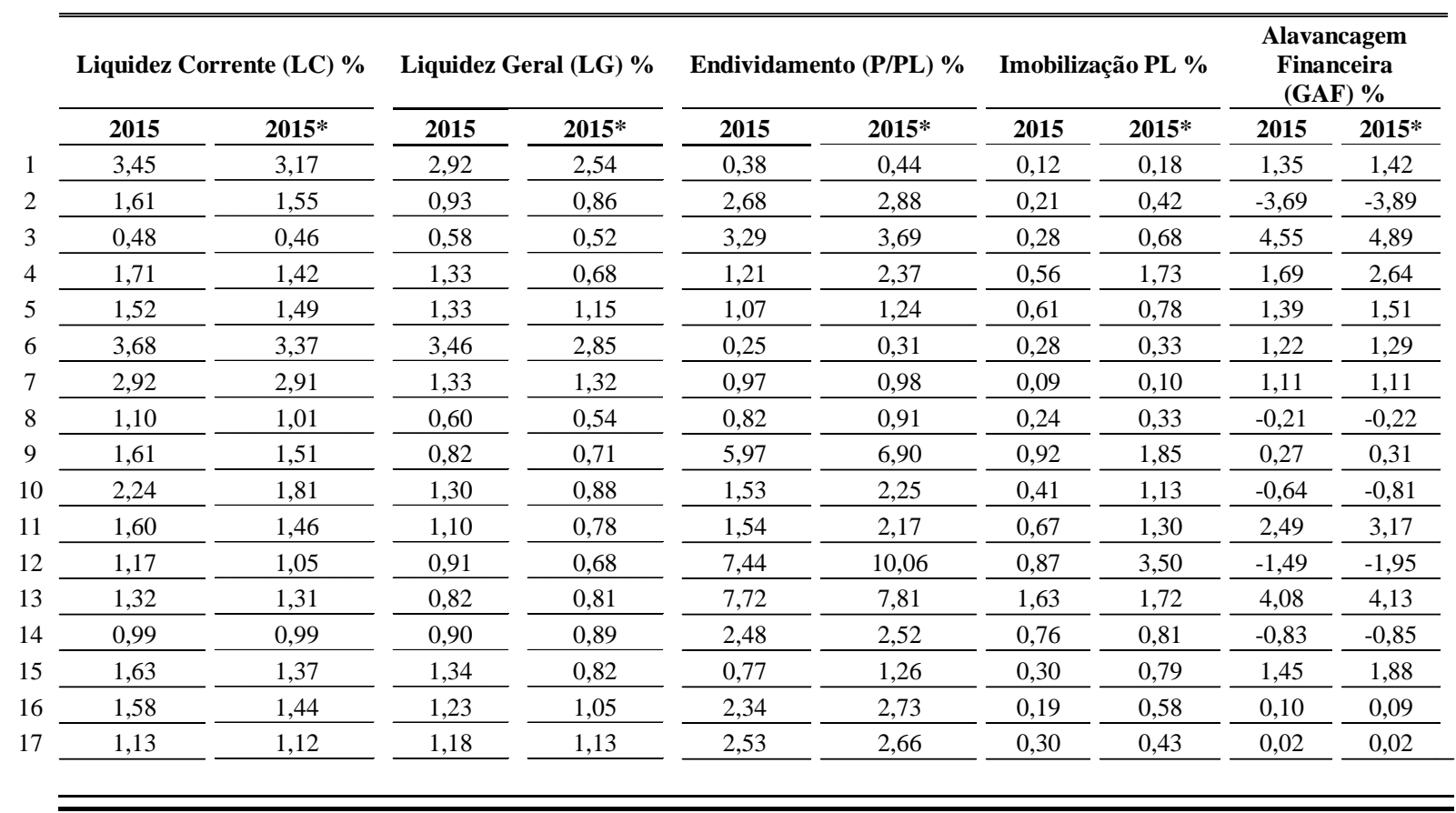

Fonte: Elaborada pelos autores, 2016.

Os resultados obtidos, considerando a adoção inicial da IFRS 16, indicaram uma redução da liquidez corrente em 16 companhias (94\%). Observou-se uma queda acentuada nas companhias Dimed S.A. (-17,2\%), Lojas Marisa S.A (-32,5) e Raia Drogasil (-15,7\%). Este efeito se dá em função do reconhecimento de dívidas de curto e longo prazo que, seguindo os preceitos do CPC 06 R1 e IAS17, não estavam contabilizadas no passivo, itens off balance.

Logo, partiu-se para a escolha do teste estatístico que fosse capaz de responder se existiriam diferenças significativas nos indicadores de liquidez, endividamento e alavancagem destas companhias antes e depois da adoção da IFRS 16.

Contudo, antes da escolha do teste estatístico para realizar as inferências acerca da amostra, foi necessário verificar se a amostra possuía distribuição normal. Para avaliar a normalidade de uma amostra os testes mais adequados são o de Kolmogorov - Smirnov (K-S) e o de Shapiro - Wilk (S-W).

O teste K-S é um teste de aderência que procura determinar se uma amostra é proveniente de uma população com distribuição normal. O teste $\mathrm{S}-\mathrm{W}$ também testa se a variância em estudo possui ou não distribuição normal.

De acordo com Maroco (2007, citado por Fávero, Belfiore, Silva \& Chan, 2009) o teste de S-W é mais apropriado que o teste K-S, quando as amostras são pequenas, $\mathrm{n}<30$. Dado o perfil da amostra em estudo, o teste escolhido foi o S-W.

Por meio do pacote estatístico SPSS, foram efetuados os Testes de Normalidade de S-W. A estatística aplicada considerou o nível de significância $\alpha=5 \%$. O SPSS calcula o pvalue que corresponde ao menor nível de significância observado que levaria à rejeição da hipótese nula. A hipótese nula H0 afirma que a amostra provém de uma população normal. A 
hipótese alternativa H1 afirma que a amostra não provém de uma população normal. Os dados obtidos são apresentados na Tabela 3.

Tabela 3 - Teste de Normalidade

\begin{tabular}{|c|c|c|c|}
\hline & & \multicolumn{2}{|c|}{ Shapiro - Wilk } \\
\hline Parâmetro & Estatística & gl. & Sig. \\
\hline Liquidez Corrente (LC) & 0,851 & 17 & 0,011 \\
\hline Liquidez Geral (LG) & 0,695 & 17 & 0,000 \\
\hline Endividamento (P/PL) & 0,800 & 17 & 0,002 \\
\hline Imobilização PL & 0,843 & 17 & 0,008 \\
\hline Alav. Financeira (GAF) & 0,776 & 12 & 0,005 \\
\hline
\end{tabular}

Ao lançar os indicadores financeiros de liquidez, endividamento e alavancagem no programa SPSS, foram obtidos os valores dos p-values. Como todos os valores dos p-values obtidos são inferiores a $5 \%(\alpha=5 \%)$, verifica-se que a amostra deste estudo não possui distribuição normal.

Dada a não normalidade da amostra, foi usado o teste não paramétrico de Wilcoxon a fim de avaliar se existiriam diferenças significativas nos indicadores de liquidez, endividamento e alavancagem antes e após a adoção da IFRS 16.

Para o teste de Wilcoxon, a hipótese nula H0 implica que os indicadores calculados com base nas informações publicadas em 2015 e os indicadores ajustados não apresentaram diferenças significativas. A hipótese $\mathrm{H} 1$ implica que os indicadores calculados com base nas informações publicadas em 2015 e os indicadores ajustados dão indícios de que existem diferenças significativas. Os dados obtidos são apresentados na Tabela 4.

Tabela 4 - Teste de Wilcoxon

\begin{tabular}{|c|c|c|c|c|}
\hline Parâmetro & $\mathbf{N}$ & $\mathbf{Z}$ & Sig. Assint. (Bilateral) & Conclusão \\
\hline Liquidez Corrente (LC) & 17 & $-2,831$ & 0,005 & Sig. $<0,05$ Rejeita-se H0 \\
\hline Liquidez Geral (LG) & 17 & $-3,215$ & 0,001 & Sig. $<0,05$ Rejeita-se H0 \\
\hline Endividamento (P/PL) & 17 & $-3,621$ & 0,000 & Sig. $<0,05$ Rejeita-se H0 \\
\hline Imobilização PL & 17 & $-3,622$ & 0,000 & Sig. < 0,05 Rejeita-se H0 \\
\hline Alava. Financeira (GAF) & 12 & $-2,756$ & 0,006 & Sig. $<0,05$ Rejeita-se H0 \\
\hline
\end{tabular}

Fonte: Elaborada pelos autores, 2016.

Com relação ao indicador de liquidez geral, as 17 companhias apresentaram um recuo, tendo como destaque as companhias Dimed S.A (-49,0\%), Lojas Marisa S.A. (-32,0\%) e Raia Drogasil (-38,8\%). Os indicadores de liquidez apresentados sinalizam a capacidade destas companhias em assumir suas dívidas. 
Nota-se, também, um aumento no nível de endividamento da amostra. Destaque para Dimed S.A. (96,2\%), Lojas Marisa (47,1\%) e Raia Drogasil (63,5\%). O índice de endividamento indica a dependência que a entidade apresenta de terceiros e, nesse sentido, o risco a que está sujeita.

Por fim, observou-se um aumento no grau de alavancagem de 12 companhias, destacando-se as companhias Dimed S.A com aumento de 56\%, Lojas Renner com aumento de $27 \%$ e Raia Drogasil com aumento de $29 \%$.

O reconhecimento do arrendamento mercantil operacional nas demonstrações contábeis das companhias de atacado e varejo, em linhas gerais, indicou diminuição da liquidez, aumento do endividamento e aumento na alavancagem.

Nota-se que as informações divulgadas pelas empresas brasileiras não estão totalmente adequadas aos requisitos do CPC 06 (R1). Iudícibus (2010b) afirma que a evidenciação é um compromisso inalienável da Contabilidade com seus usuários, pois a apresentação das informações quantitativas e qualitativas propiciam base adequada de informação para os usuários. Dessa forma, nota-se a relevância do processo de evidenciação e divulgação das informações na medida em que estas procuram atender diferentes tipos de usuários.

\section{CONSIDERAÇÕES FINAIS}

O estudo teve por objetivo avaliar o impacto da adoção da IFRS 16 nos indicadores das companhias de atacado e varejo listadas na bolsa de valores brasileira, tendo como base as mudanças causadas nos principais indicadores.

Para atingir o objetivo proposto, foi necessário seu desmembramento em três objetivos específicos: i) identificar o nível de disclosure evidenciado em notas explicativas das companhias abertas que possuem contratos de arrendamento mercantil operacional na qualidade de arrendatárias, ii) mensurar os impactos concretizados pela IFRS 16 nos demonstrativos contábeis das companhias de capital aberto, na qualidade de arrendatárias e iii) avaliar o impacto, a partir das propostas da IFRS16, na estrutura de capital das companhias que possuem contratos de arrendamento mercantil operacional, na qualidade de arrendatárias.

Os resultados obtidos sugerem que o leasing produz efeitos sob a liquidez, o endividamento e também sobre a alavancagem operacional.

Cabe ressaltar que os resultados obtidos corroboram pesquisas anteriores - Barbosa, Barros, Niyama e Souza (2011), Gallon, et al (2012), Batista e Formigoni (2013) - sobre os impactos do arrendamento mercantil na estrutura de ativos e passivos e nos indicadores financeiros.

Limitação relevante para o estudo é o fato de que muitas companhias não apresentaram em suas informações de 2015 a recomendação que o CPC 06 R1 propõe no tocante ao nível de disclosure necessário à divulgação das operações de arrendamento mercantil. Adicionalmente, não fizeram parte do escopo do trabalho, representando desta 
forma uma limitação, os efeitos da mensuração subsequente da IFRS 16. Não foram consideradas as taxas de depreciação dos ativos relativos ao arrendamento operacional, taxas de desconto para o cálculo do valor presente das parcelas futuras.

Sugere-se que em estudos futuros sejam abordados, comparativamente, os impactos das alterações analisadas no presente trabalho em segmentos distintos, com a finalidade de identificar como cada um deles se comporta, permitindo uma maior compreensão da realidade de cada atividade.

\section{REFERÊNCIAS}

Assaf, A.N. (2012). Finanças Corporativas e Valor, 6ª ed, São Paulo: Atlas.

Editorial. (2015, junho/junho). Anuário Estatístico das Companhias Abertas 2015/2016, 10(11), 130.

Comitê de Pronunciamentos Contábeis. (2010). CPC 06 R1 Operações de Arrendamento Mercantil. Brasília, DF: Comitê de Pronunciamentos Contábeis.

Gallon, A. V.; Crippa, M.; Gois, A. F.; De Luca, M. M.; (2012). As mudanças no tratamento contábil do leasing e seus reflexos nos indicadores econômico financeiros: as companhias aéreas brasileiras. Revista de Finanças Aplicadas . Publicado em 13dez12, pp.1-18. Acesso em: 28 de agosto de 2016, de http://www.financasaplicadas.net/index.php/financasaplicadas/article/view/79 .

International Accounting Standards Board. (2010a). IAS 17 Leases. London: Author.

International Accounting Standards Board. (2010b). Exposure Draft 2010/9 Leases. London: Author.

International Accounting Standards Board. (2013). Exposure Draft 2013/6 Leases. London: Author

International Accounting Standards Board. (2015). Leases: Pratical implications of the new Leases Standard. London: Author

International Accounting Standards Board. (2016). IFRS Standard 16 Leases. London: Author

Iudícibus, S.D., Martins, E., Gelbecke, E.R., Santos, A.D. (2013). Manual de Contabilidade Societária, $2^{\mathrm{a}}$ ed, São Paulo: Atlas.

Iudícibus, S.D. (2010a). Análise de Balanços, 10ª ed, São Paulo: Atlas.

Iudícibus, S.D. (2010b). Teoria da Contabilidade, 10ªed. São Paulo: Atlas. 
Lei n 6.099, de 12 de setembro de 1974. (1974, 13 de setembro). Dispõe sobre o tratamento tributário das operações de arrendamento mercantil e dá outras providências. Diário Oficial da União, seção 1 .

Lei n 6.404/76, de 15 de dezembro de 1976. (1976, 17 de dezembro). Dispõe sobre as sociedades por ações. Diário Oficial da União, seção 1.

Lei n 7.132, de 26 de outubro de 1983. (1983, 27 de outubro). Altera a Lei n ${ }^{0}$ 6.099, de 12 de setembro de 1974, que "dispõe sobre o tratamento tributário de arrendamento mercantil, e dá outras providências" e o Decreto-lei nº 1.811, de 27 de outubro de 1980. Diário Oficial da União, seção 1.

Lei n 11.638, de 15 de dezembro de 1976. (1976, 28 de dezembro). Altera e revoga dispositivos da Lei $\mathrm{n}^{0}$ 6.404, de 15 de dezembro de 1976, e da Lei ${ }^{\circ} 6.385$, de 7 de dezembro de 1976, e estende às sociedades de grande porte disposições relativas à elaboração e divulgação de demonstrações financeiras. Diário Oficial da União, seção 1.

Martins, E.; Miranda, G.J.; Diniz, J.A. (2014). Análise didática das demonstrações contábeis, São Paulo: Atlas S.A.

Matarazzo, D.C. (2010) Análise financeira de balanços: abordagem gerencial, $7^{\mathrm{a}}$ ed. São Paulo: Atlas.

Niyama, J.; Barbosa, G.; Barros, F. O.; Barbosa; G. C.; Souza, L. M. (2011, janeiro/abril). Impacto da contabilização do leasing operacional no balanço patrimonial: o caso das Cias. Aéreas brasileiras TAM e GOL. Enfoque: Reflexão Contábil, 30 (1), 21-34. Acesso em 21 de setembro de 2015, de http://periodicos.uem.br/ojs/index.php/Enfoque/article/view/13178.

Niyama, J. K., Silva,C. A. (2013). Teoria da Contabilidade, $3^{a}$ ed, São Paulo: Atlas S.A.

Resolução CFC n 1.055 de 07 de outubro de 2005. (2005,24 de outubro). Cria o COMITÊ DE PRONUNCIAMENTOS CONTÁBEIS - (CPC), e dá outras providências. Diário Oficial da União.

Ribeiro, E. M. (2015). Leasing internacional é uma vigorosa ferramenta de inversão: novas regras contábeis. São Paulo: Boletim Abel Especial, 1(203), 13-15.

Funaro, V. M. B. O, Pestana, M. C., Garcia, E. M., Rebello, M. A. F., Avello, M. A. B., Carvalho, M. J. J., Nascimento, M. M., Paschoalino, R. A., Cardoso, S. C., \& Lombardi, V. V. Diretrizes para apresentação de dissertações e teses da USP: documento eletrônico e impresso. Parte II (APA). São Paulo: Universidade de São Paulo. Acesso em 28 de Agosto de 2016, de

http://www.teses.usp.br/index.php?option=com_phocadownload\&view=category\&id=2\%3Ad iretrizes\&download=6\%3Aparte-ii-apa\&Itemid=124\&lang=pt-br .

Vergara, S. C.(2014). Projetos e Relatórios de Pesquisa em Administração, 15ª ed, São Paulo: Atlas S.A. 